\title{
Mathematical models with equations for re-conversion of private debt.
}

\author{
García-Santillán, Arturo \\ Misantla Institute Technology (MIT) \\ \& UCC Business School \\ agarcias@tsm.edu.mx, agarcias@ucc.mx
}

\begin{abstract}
The current health crisis derived from COVID 19 has become a serious threat to humanity. The collateral effects related to economic aspects are affecting companies, workers and, of course, families in general. The problems of financial insolvency are frequently present in debtors who have contracted a debt with their creditor. Therefore, the objective of the study is focused on modeling a debt restructuring proposal, through three hypothetical scenarios in which the debt is reconvened when some documents have expired and others are yet to expire. In each of the scenarios, the mathematical model is designed and subsequently corroborated in an Excel spreadsheet. The predominant variables in the restructuring are the adjustment rates used to update the past due promissory notes and the discount rates of those promissory notes that have not yet expired, capitalizations, transaction costs and, if applicable, whether the debt is in foreign currency. In this case, it is converted to the local currency, then the spot exchange rate is used.

Keywords: Debt, re-conversion, equations
\end{abstract}

\section{Introduction.}

Constant adjustments in the world economy affect practically every activity carried out by human beings. The global crisis due to the COVID-19 virus has become a threat to humanity. The efforts of different countries to find a cure, or at least, treatment that can counteract this evil that afflicts humanity, have not yet been definitive but great progress has been made. However, beyond that are the collateral effects of this crisis, including those related to the economy, that afflicts countries and their governments. These have impacted a different productive sector, where companies and individual workers have been greatly affected, which generates a very strong collateral damage to families.

With these reflections what is sought in this study is not to find a solution to this crisis in the equation model, but to offer a proposal so that individuals who have contracted debt and face financial insolvency problems can reach a good agreement to restructure their debt. The model seeks a balance between the parties (Debtor and Creditor)

As the Institute of Corporate Finance (Corporate Finance Institute, 2019) points out, debt restructuring constitutes a process in which an entity, company or person experiences an adverse financial situation in meeting previously incurred debt obligations. The lack of liquidity forces a search for a flexible option in the short term, which allows making debt payment more manageable. With these arguments, it is sought to define the routes of possible hypothetical scenarios under which a debt restructuring can be carried out.

\section{Theoretical development of the mathematical model}

The development of a debt restructuring model through a set of equivalent equations begins with a proposal by García-Santillán and Vega-Lebrúm in 2008. They propose an algorithm with equations of simple and compound interest, considering only the interest rates for indexation in the case of overdue promissory notes and a discount rate, in the case of promissory notes that have not yet matured within the time line previously agreed between the parties, the debtor and the creditor. 
For the debt valuation, they consider the ordinary interest or accurate interest $(\mathrm{t} / 360$ or $\mathrm{t}$ / 365) as agreed:

$$
\begin{gathered}
V_{D O}=\frac{D_{O_{1}}}{\left(1+\frac{i_{1} t_{1}}{360}\right)} \text { and } V_{D O}=\frac{D_{O_{1}}}{\left(1+\frac{i_{1} t_{1}}{365}\right)} \\
V_{D O}=\frac{D_{O_{1}}}{\left(1+\frac{i_{j} t_{j}}{360}\right)}+\ldots+V_{D O}=\frac{D_{O_{1}}}{\left(1+\frac{i_{j} t_{j}}{360}\right)} \text { and } V_{D O}=\frac{D_{O_{1}}}{\left(1+\frac{i_{j} t_{j}}{365}\right)}+\ldots+V_{D O}=\frac{D_{O_{1}}}{\left(1+\frac{i_{j} t_{j}}{365}\right)}
\end{gathered}
$$

In the same proposal, the capitalization variable was integrated; that is, the effect of compound interest that modifies the indexing or discount index as the case may be, due to the inclusion of the exponent.

$$
\begin{gathered}
V_{D O}=\frac{D_{O_{1}}}{\left(1+\frac{i_{1} t_{1}}{360}\right)^{m}} \quad \text { and } \quad V_{D O}=\frac{D_{O_{1}}}{\left(1+\frac{i_{1} t_{1}}{365}\right)^{m}} \\
V_{D O}=\frac{D_{O_{1}}}{\left(1+\frac{i_{j} t_{j}}{360}\right)^{m}}+\ldots+V_{D O}=\frac{D_{O_{1}}}{\left(1+\frac{i_{j} t_{j}}{360}\right)^{m}} \text { and } V_{D O}=\frac{D_{O_{1}}}{\left(1+\frac{i_{j} t_{j}}{365}\right)^{m}}+\ldots+V_{D O}=\frac{D_{O_{1}}}{\left(1+\frac{i_{j} t_{j}}{365}\right)^{m}}
\end{gathered}
$$

With these basic equations, they built an algorithm that will cover a timeline in the three possible moments to revalue a debt. Firstly those promissory notes that had already expired (bff) and had to adjust to a certain focal date, followed by the promissory note or notes that coincide on the same focal date ( $f f$ agreed) and finally, the promissory notes that had not yet matured (aff); that is, they had not expired. In this way, the following model of equivalent equations for the new debt was defined:

The model with accurate simple interest

$$
V_{D N}=\sum_{1 \ldots j}^{b f d} S_{1_{a f d}}\left(1+\frac{i_{1} t_{1}}{365}\right)+\ldots S_{j}\left(1+\frac{i_{j} t_{j}}{365}\right)+S_{f f}+\sum_{1 \ldots j}^{a f d} S_{1_{p f d}} /\left(1+\frac{i_{1} t_{1}}{365}\right)+\ldots S_{j_{p p d}} /\left(1+\frac{i_{j} t_{j}}{365}\right)
$$

The model with compound interest

$$
V_{D N}=\sum_{1 \ldots . . j}^{b f d} S_{1_{a f d}}\left(1+\frac{i_{1} t_{1}}{365}\right)^{t / m}+\ldots S_{j}\left(1+\frac{i_{j} t_{j}}{365}\right)^{t / m}+S_{f f}+\sum_{1 \ldots . j}^{a d f} S_{1_{p f d}} /\left(1+\frac{i_{1} t_{1}}{365}\right)^{t / m}+\ldots S_{j_{d f d d}} /\left(1+\frac{i_{j} t_{j}}{365}\right)^{t / m}
$$

In both cases, the suggestion is to replace the $S$ of the amount by $X$, whose value is the unit (1). Resulting $\mathrm{S}_{b f d}, S_{f d}$ and $S_{a f d}$ by $X_{b f d}, X_{f d}$ and $X_{a f d}$. In addition, we must considering if is accurate interest or compound interest. Therefore, the exponent of the latter is integrated $(\mathrm{t} / \mathrm{m})$

$$
V_{D N}=\sum_{1 \ldots j}^{b f d} X_{1_{d f d}}\left(1+\frac{i_{1} t_{1}}{365}\right)^{t / m}+\ldots X_{j}\left(1+\frac{i_{j} t_{j}}{365}\right)^{t / m}+X_{d f}+\sum_{1 \ldots j}^{a d f} X_{1_{p f d d}} /\left(1+\frac{i_{1} t_{1}}{365}\right)^{t / m}+\ldots X_{j_{p f d d}} /\left(1+\frac{i_{j} t_{j}}{365}\right)^{t / m}
$$




$$
V_{D N}=\sum_{1 \ldots j}^{b f d} 1_{1_{\text {aff }}}\left(1+\frac{i_{1} t_{1}}{365}\right)^{t / m}+\ldots 1_{j}\left(1+\frac{i_{j} t_{j}}{365}\right)^{t / m}+1_{f f}+\sum_{1 \ldots j}^{a f d} 1_{1_{a f d}} /\left(1+\frac{i_{1} t_{1}}{365}\right)^{t / m}+\ldots 1^{j_{d f d}} /\left(1+\frac{i_{j} t_{j}}{365}\right)^{t / m}
$$

They even simplified the equations, ie, the coefficient that multiplies the values $b f d$ and / or afd is denoted as $F_{a}$, which in every case replaces the coefficient $\left(1+\left(i_{1} t_{1} / 365\right)\right.$ for the simple interest and $\left(1+\left(i_{1} t_{1} / 365\right)^{t / m}\right.$ for the compound interest. This leaves the following expression:

$$
\begin{aligned}
& \text { Simple interest } \quad V_{D N}=\sum_{1 \ldots j}^{b f d} 1_{b_{b d d}}\left(F_{a}\right)+\ldots 1_{j}\left(F_{a}\right)+1_{f d}+\sum_{1 \ldots j}^{a f d} 1_{1_{p f f}} /\left(F_{a}\right)+\ldots 1_{j_{d f d}} /\left(F_{a}\right) \\
& \text { Compound interest } \quad V_{D N}=\sum_{1 . . . j}^{b f d} 1_{1_{b f d}}\left(F_{a}\right)^{t / m}+\ldots 1_{j}\left(F_{a}\right)^{t / m}+1_{f f}+\sum_{1 \ldots . j}^{a f d} 1_{1_{p d d}} /\left(F_{a}\right)^{t / m}+\ldots 1_{j_{d f d}} /\left(F_{a}\right)^{t / m}
\end{aligned}
$$

With equation 3.5 they propose to simplify the notation, each coefficient being represented according to its expiration date on the time line as follows: $C_{b f d}, C_{f d}$ and $C_{a f d}$.

Therefore, to obtain the value of the new $\operatorname{debt}(Y)$, the following equation is obtained.

$$
V_{D N}=Y\left(\sum_{1 \ldots j}^{b f d} C_{b f d}+C_{f d d}+\sum_{1 \ldots . j}^{a f d} C_{a f d d}\right), \text { we solve for " } Y \text { ". Now we have } Y=V_{D N} /\left(\sum_{1 \ldots j}^{b f d} C_{b f d}+C_{f d d}+\sum_{1 \ldots j}^{a f d} C_{a f d d}\right)
$$

Where:

$Y=$ Value of each payment

$V_{D n}=$ Value of previously appraised debt

$\left(\sum_{1 \ldots . j}^{b f d} C_{b f d}\right)=$ Sum of the coefficients of promissory notes prior to the focal date

$C_{f d}=$ Payment coefficients at the focal date

$\sum_{1 \ldots . j}^{a f d} C_{a f d}=$ Sum of the coefficients of subsequent promissory notes at the focal date

This restructuring model was modified in terms of the notation of the equations, depending on the language in which it was used, but in its mathematical form, the original idea remained. Subsequently, a variable arises that modifies the algorithm, that is, from the original proposal of García-Santillán and Vega-Lebrúm (2008) to García-Santillán, Venegas-Martínez and Escalera-Chávez, (2014), there is a significant change in interest rates. That is, GarcíaSantillán, Howe and Venegas-Martínez (2016) suggest that the interest rate be considered in the following way. For documents that have not been paid in a timely manner, the focal date must be updated, considering the effective interest rate $\left(E_{i r}\right)$ and for the valuation of the documents that were not past due, the real interest rate $\left(R_{i r}\right)$ should be used.

Derived from this proposal, the originally proposed algorithm was not modified in its essence; only the type of interest rate that was suggested to be used was modified. In this way, the equation model is as follows: 
a.- Valuing the original debt using the effective interest rate and the real interest rate, for the indexation of the expired documents and for the discount of the promissory notes not yet overdue.

$$
V_{O D}=\Sigma P N_{1 \ldots j_{b f d}}\left[1+\left(\frac{E_{i r}}{t} * m\right)\right]^{t / m}+P N_{x \ldots j_{f d}}+\frac{\Sigma P N_{1 \ldots j_{a f d}}}{\left[1+\left(\frac{R_{i r}}{t} * m\right)\right]^{t / m}}
$$

Which can be used interchangeably with; $i_{i n d x}$ by $E_{i r}$, as well as, $i_{d}$ by $R_{i r}$. Giving as resulting, the following expression.

$$
V_{O D}=\sum_{1 \ldots j}^{b f d} P_{N 1}\left[1+\left(\frac{i_{i n d x}}{m}\right)\right]^{\Sigma t / m}+\ldots+P_{N j}\left[1+\left(\frac{i_{i n d x}}{m}\right)\right]^{\Sigma t / m}+P_{N f d}+\sum_{1 \ldots j}^{a f d} \frac{P_{N 1_{a f d}}}{\left.1+\left(\frac{i_{d}}{m}\right)\right]^{t / m}}+\ldots+\frac{P_{N j_{a f d}}}{\left[1+\left(\frac{i_{d}}{m}\right)\right]^{t / m}}
$$

b.- Evaluate the new payment scheme. At this point, the number of payments of the new debt is established, so the values of each promissory note are replaced by $X$, which represents the unit (1):

$$
\begin{aligned}
& V_{N S P}=\sum_{1 \ldots . j}^{b f d} X_{n 1}\left[1+\left(\frac{i_{i n d x}}{m}\right)\right]^{\Sigma t / m}+\ldots+X_{n j}\left[1+\left(\frac{i_{i n d x}}{m}\right)\right]^{\Sigma t / m}+X_{f d}+\sum_{1 \ldots j}^{a f d} \frac{X_{n 1_{d f d}}}{\left[1+\left(\frac{i_{d}}{m}\right)\right]^{t / m}}+\ldots+\frac{X_{n j_{d f d}}}{\left[1+\left(\frac{i_{d}}{m}\right)\right]^{t / m}} \\
& V_{N S P}=\sum_{1 \ldots . . j}^{b f d} 1_{n 1}\left[1+\left(\frac{i_{i n d x}}{m}\right)\right]^{\Sigma t / m}+\ldots+1_{n j}\left[1+\left(\frac{i_{i n d x}}{m}\right)\right]^{\Sigma t / m}+1_{f d}+\sum_{1 \ldots . j}^{a f d} \frac{1_{n 1_{d f d}}}{\left.1+\left(\frac{i_{d}}{m}\right)\right]^{t / m}}+\ldots+\frac{1_{n j_{f f d}}}{\left[1+\left(\frac{i_{d}}{m}\right)\right]^{t / m}}
\end{aligned}
$$

If the effective interest rate to update the values and the real interest rate for the discount are used, we now have the following expression:

$$
V_{N S P}=\sum_{1 \ldots j}^{b f d} 1_{n 1}\left[1+\left(\frac{E_{i r} * m}{t} *\right]^{\Sigma t / m}+\ldots+1_{n j}\left[1+\left(\frac{\left.E_{i r} * m\right)}{t}\right]^{\Sigma t / m}+1_{f d}+\sum_{1 \ldots j}^{a f d} \frac{1_{n 1_{q d d}}}{\left[1+\left(\frac{R_{i r}}{t} * m\right)\right.}\right]\right]^{t / m}+\ldots+\frac{1_{n j_{d f d}}}{\left[1+\left(\frac{R_{i r}}{t} * m\right)\right]^{t / m}}
$$

c.- To find the value of $Y$ in case of equal payments in the restructuring, we have the following expression:

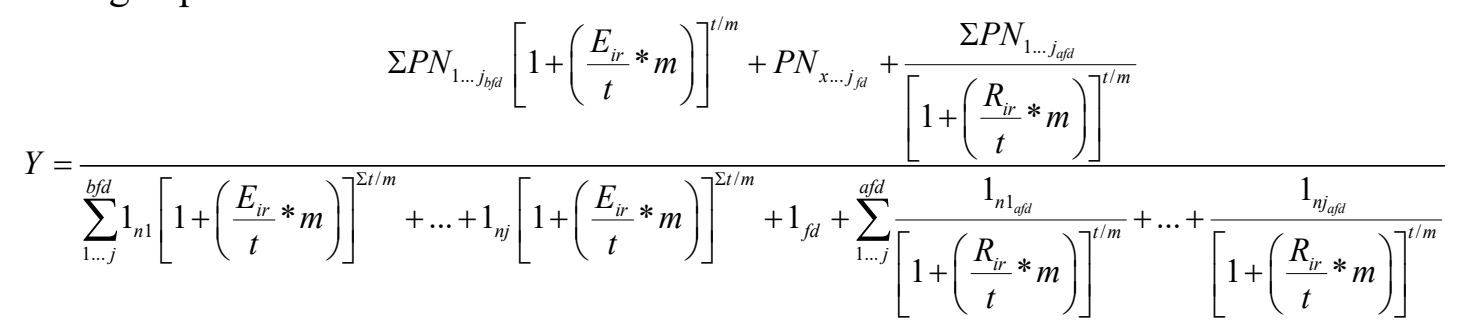

Or, if applicable, the following equation can be used 


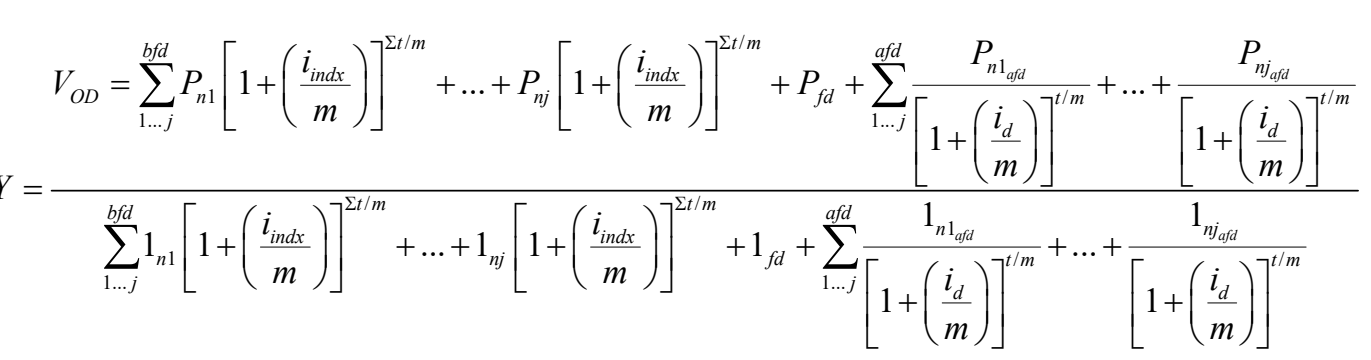

Table 1 describes the notation of the previously stated formulas.

Table 1.

Formula notation

\begin{tabular}{cl}
\hline Notation & \\
\hline$f d$ & Focal date \\
$b f d$ & Before focal date \\
$a f d$ & After focal date \\
$i_{d / m}$ & Accurate interest rate (discounting) $\left(\sum i_{d} / 365^{*} m\right)$ \\
$i_{\text {indx } m}$ & Accurate interest rate (indexing) $\left(\sum i_{\text {ind } x} / 365^{*} m\right)$ \\
$P_{1}$ & $1^{\text {th }}$ Promissory note \\
$M$ & Capitalization \\
$N$ & Time $\left(\sum t / m\right)$ \\
$V_{O D}$ & Original valuation \\
$V_{N S P}$ & New scheme valuation \\
$Y 1 \ldots j$ & Equal payments \\
$E_{i r}$ & Effective interest rate \\
$R_{i r}$ & Real interest rate \\
\hline
\end{tabular}

\section{Source: own}

The model continued to be applied in this format, until the proposal by García-Santillán (2019) which evaluates the pertinence of including the variable Transaction costs. This is considered a variable that favored the creditor, who, in the absence of payment by his debtor, turned out to be the most affected party as non-compliance generated additional costs.

In this way, one starts from the original proposal; $5,5.1,5.2 .3$ or $5.2 .3 \mathrm{~b}$ to give way to the new proposal by García-Santillán (2019) for debt restructuring. Here, he suggests including the variable "Transaction Cost" as part of the requirements of negotiation that the creditor would carry out with his debtor. Therefore, the mathematical model must be restructured based on the prorated function according to the amount of each restructured promissory note, in relation to the total revalued debt. To do this, the transaction cost coefficient must be calculated for each of the promissory notes that make up the revalued debt from the following function:

$$
T C C=\frac{V_{O D}}{P_{N_{1 . . j}} \ldots} \quad(6) \quad \text { and } \quad T C A=V_{O D} * i_{t c e}
$$

Where:

$T C C=$ Transaction cost coefficient

$T C A=$ Transaction cost amount

$P N=$ Promissory notes $(1$ to $j)$ 
$V_{O D}=$ Value of the original debt

$i_{\text {tce }}=$ Estimated transaction cost rate (agreed in the renegotiation)

In this way, the proposal of García-Santillán (2019) establishes the following mathematical function to demonstrate:

$$
\begin{aligned}
& V_{O D} \\
& \text { by } \\
& V_{\text {ODadjusted }} \\
& Y_{1 \ldots j}=\frac{V_{O D}}{V_{N S P}} \\
& \text { by }
\end{aligned}
$$

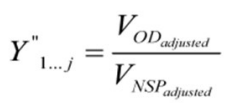

Then from (5.1)

$V_{O D}=\sum_{1 \ldots j}^{b f d} P_{N 1}\left[1+\left(\frac{i_{i n d x}}{m}\right)\right]^{\Sigma t / m}+\ldots+P_{N j_{b f d d}}\left[1+\left(\frac{i_{i n d x}}{m}\right)\right]^{\Sigma t / m}+P_{N f d}+\sum_{1 \ldots j}^{a f d} \frac{P_{N 1_{a f d}}}{\left[1+\left(\frac{i_{d}}{m}\right)\right]^{t / m}}+\ldots+\frac{P_{N j_{\text {qfd }}}}{\left[1+\left(\frac{i_{d}}{m}\right)\right]^{t / m}}$

It now becomes:

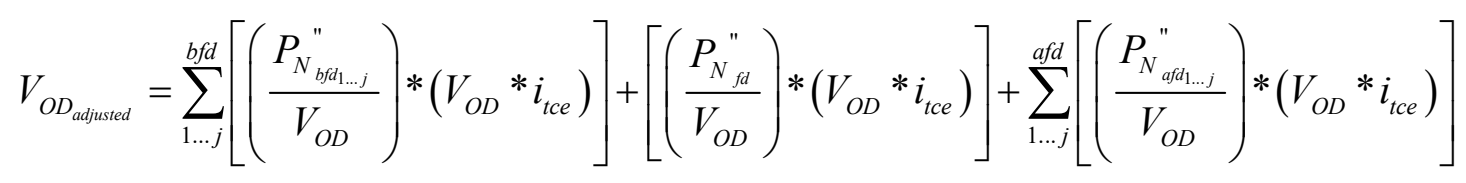

Where:

$V_{O D_{\text {adjusted }}}=$ Value of the adjusted original debt;

$P_{N_{b f d_{1 \ldots j}}^{\prime \prime}}^{\|}=$Promissory notes revaluated before focal date;

$P_{N_{f d}}^{\prime \prime}=$ Promissory notes revaluated in the focal date;

$P_{N_{a f d_{1 . j} j}^{\prime \prime}}=$ Promissory notes revaluated after focal date;

$i_{\text {tce }}=$ Estimated transaction cost rate (agreed in the renegotiation);

$V_{O D}=$ Value of the original debt revaluated.

expression

Now the equation equivalent model is represented by the following mathematical 


$$
\begin{aligned}
& V_{O D_{a d j u s t e d}}=\sum_{1 \ldots j}^{b f d}\left[\left(\frac{P_{N_{b f d_{1 . \ldots j} j}^{\prime \prime}}^{\prime}}{V_{O D}}\right) *\left(V_{O D} * i_{t c e}\right)\right]+\left[\left(\frac{P_{N_{f d}}^{\prime \prime}}{V_{O D}}\right) *\left(V_{O D} * i_{t c e}\right)\right]+\ldots \\
& Y_{1 \ldots j}^{\prime \prime}=\frac{\ldots+\sum_{1 \ldots j}^{a f d}\left[\left(\frac{P_{N_{a f d_{1} \ldots j}}}{V_{O D}}\right) *\left(V_{O D} * i_{t c e}\right)\right]}{V_{N S P_{a d j u s t e d}}}=\sum_{1 \ldots j}^{b f d} 1_{1}\left[1+\left(\frac{E_{i r} * m}{t}\right)\right]^{2 t / m}+\ldots+1_{j}\left[1+\left(\frac{\left.\left.E_{i r} * m\right)\right]^{2 t / m}+1_{f d}+\ldots}{t}\right.\right. \\
& \sum_{1 \ldots j}^{a f d} \frac{1_{1_{a f d}}}{\left[1+\left(\frac{R_{i r}}{t} * m\right)\right]^{t / m}}+\ldots+\frac{1_{j_{a f d}}}{\left[1+\left(\frac{R_{i r}}{t} * m\right)\right]^{t / m}}
\end{aligned}
$$

In this way, we can obtain the value $Y^{\prime \prime}{ }_{1 \ldots j}$ that represents the revalued amount of each of the original debt payments that will be restructured by a new payment scheme. This includes the apportionment of transaction costs that have previously been agreed between the parties. In this mathematical expression, the validity moments of each document are still considered, that is, those that were not paid at maturity were called promissory notes that were on the timeline before the focal date $(b f d)$, those that were in the focal date $(f d)$ and those that in the timeline were after the focal date $(a f d)$. In this part, it is essential to have a defined focal date; since it is from this that all documents must be updated on that date. In the case of documents that have expired, they are updated at the focal date and those that are not expired are brought at a discount to the focal date. If there were any on the focal date, their value is the same, although the agreed proration of transaction costs applies. In this way, you will be able to develop the model of equivalent equations more fairly between the parties.

\section{Inclusion of the spot exchange rate variable}

At the same time, García-Santillán (2019b) assesses the relevance of including the exchange rate variable, which would allow currency conversion, depending on the type of currency in which it was originally agreed the debt and the subsequent conversion to another currency, for example, from dollars to Mexican pesos. Commercial and banking credit or loan operations are often agreed in a currency different from that of the country where the operation is carried out.

As an example of this, in Mexico, operations can be in dollars or Euros, to name a few currencies. In this way, the algorithm with equations is adapted with the inclusion of the variable $\left(S_{E R}\right)$, the equation being modified 10 by 11 : 


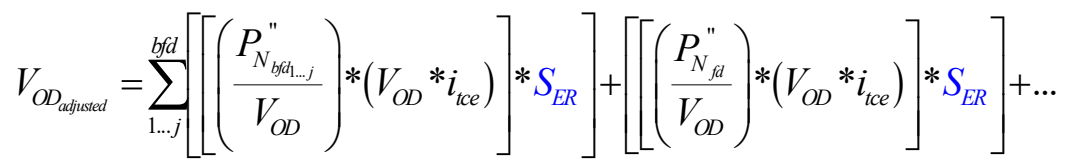

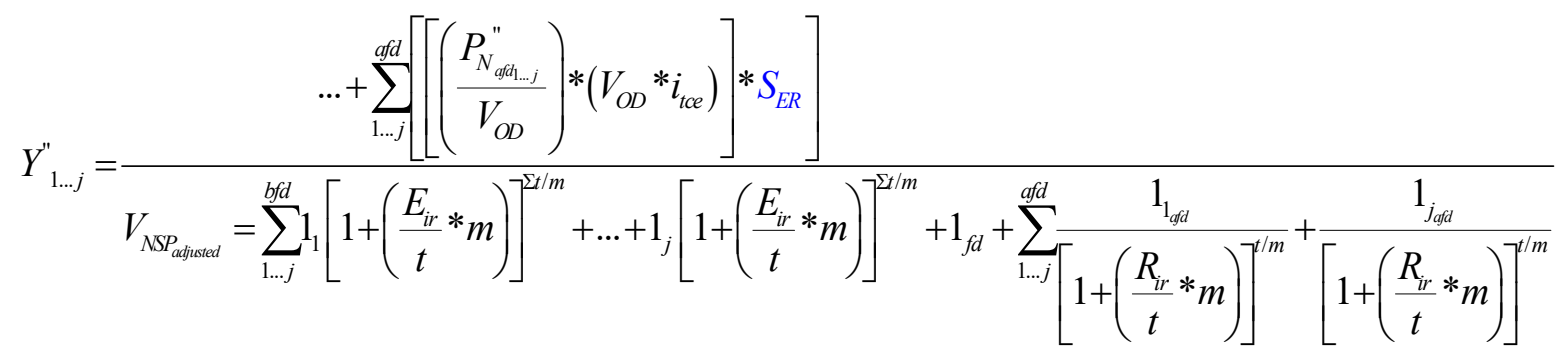

In this way, the algorithm of equivalent equations was designed to restructure debts, in the event of possible contingencies. However, doubts will always arise that question the model. One of them may be: For a possible hypothetical scenario 1; what is the mathematical model that best suits when all the documents have expired? For a following hypothetical scenario 2 what is the model that can be applied in the absence of documents that have expired, but that the debtor presumes that he will not be able to cover in the times agreed in each one of them, or even on the focal date? And finally, the relevance of a hypothetical scenario is questioned in which equal payments are not necessarily agreed in the new payment scheme. That is, some specific amounts are agreed in some documents.

\section{To answer the question of scenario 1}

In the event that all the documents have expired and you want to restructure in a certain number of equal payments, all after a focal date, now the equation model is represented as follows.

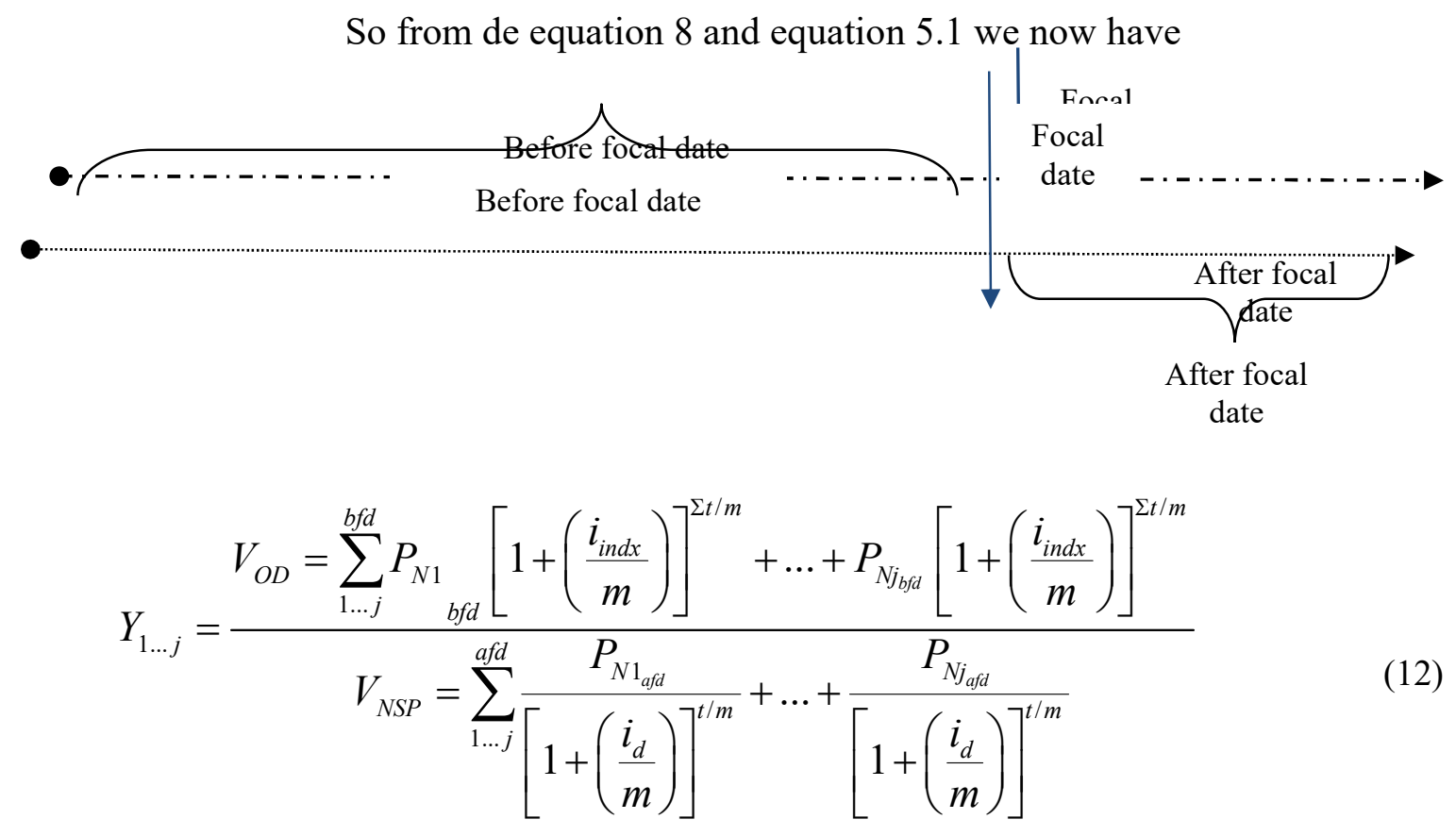


Same case, only now the transaction costs are agreed; the currency conversion from dollars to Mexican pesos is required. Then, the model is modified:

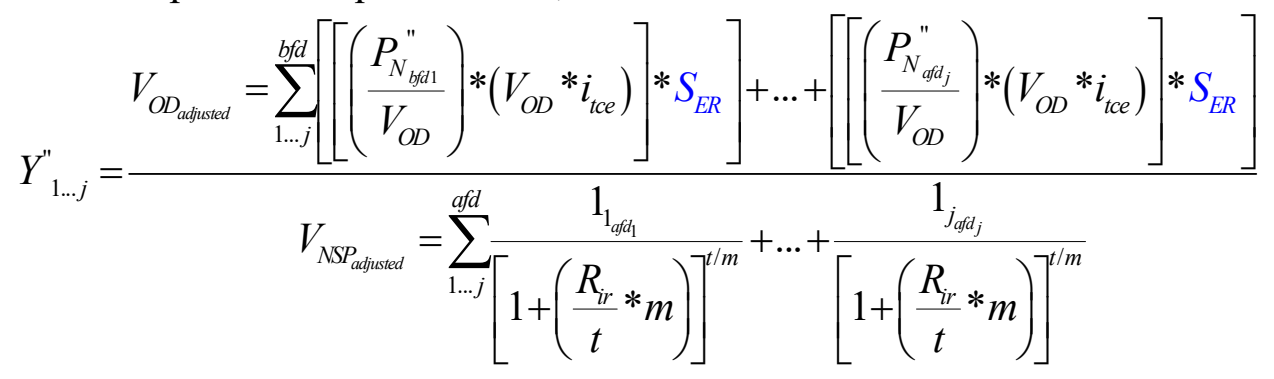

\section{Now, to answer the question in scenario 2}

In this scenario, there are no expired documents, but the debtor considers that he will not be able to pay the debt in the same terms in which it was agreed. Therefore, the debtor asks the creditor for a restructuring proposal in the following terms: a payment on the focal date and the rest of the debt in subsequent payments after the focal date. Hence, the equation model is modified as follows.

First, the original debt must be revalued using the effective interest rate and the real interest rate, for the indexation of the expired documents and for the discount of the promissory notes not yet due, as the case may be. As there are no expired documents, we use formula 5 and now we have:

$$
V_{O D}=\Sigma P_{N_{1 . \ldots j a f d}} \frac{P_{N 1_{a f d}}}{\left[1+\left(\frac{R_{i r}}{t} * m\right)\right]^{t / m}}+\ldots+\frac{P_{N j_{a f d}}}{\left[1+\left(\frac{R_{i r}}{t} * m\right)\right]^{t / m}}
$$

That can be used interchangeably with $i_{\text {indx }}$ for $E$ ir as well as $i_{d}$ by $R$ ir $(5.1$.

$$
V_{O D}=\sum_{1 \ldots j}^{a f d} \frac{P_{N 1_{a f d}}}{\left[1+\left(\frac{i_{d}}{m}\right)\right]^{t / m}}+\ldots+\frac{P_{N j_{a f d}}}{\left[1+\left(\frac{i_{d}}{m}\right)\right]^{t / m}}
$$

Once each document has been revalued, the proposal for the new payment scheme is now designed, which may include the variable transaction costs and debt conversion, in a case where the debt is in Mexican pesos and it is required to convert to dollars, as shown in the following timeline:

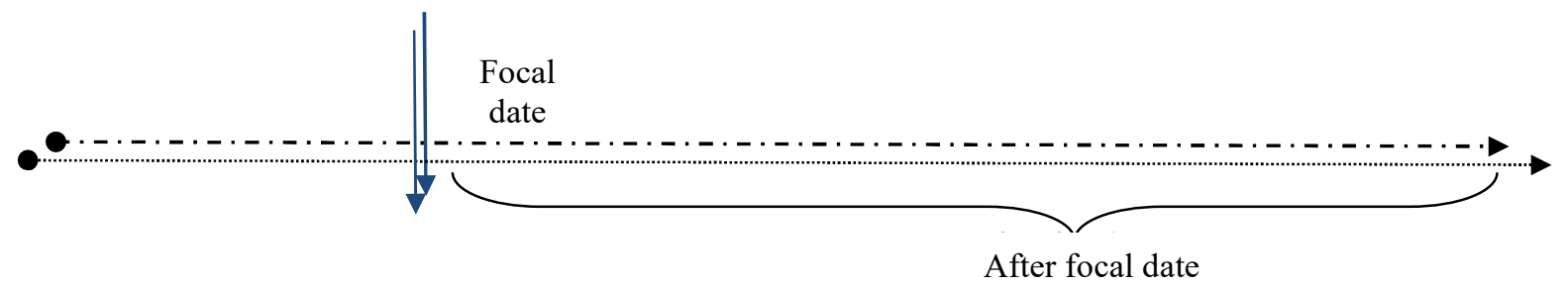

The value of each promissory note that has been previously revalued ( $\left.P_{\text {Nafd }_{1}}\right)$; it is integrated with the apportionment of the agreed transaction costs and the currency conversion. In this way, the value of each payment $\left(Y^{\prime \prime}{ }_{1 \ldots j}\right)$ in the new scheme will be given by the following equation: 


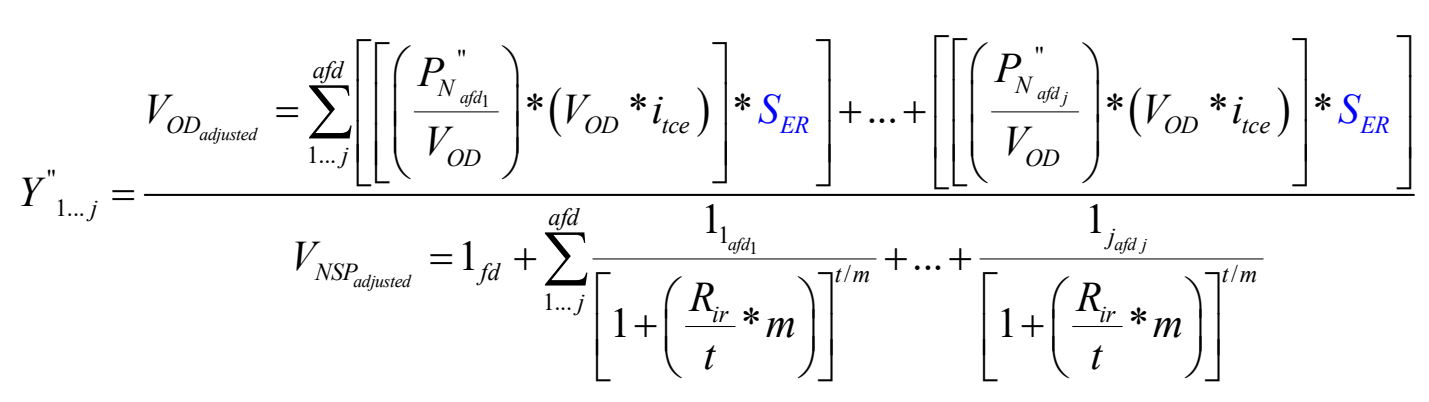

\section{For scenario 3}

The relevance of a hypothetical is questioned in which equal payments are not necessarily agreed in the new payment scheme; that is, some specific amounts are agreed in some documents. An example of this is: if there were 10 payments after the focal date, 7 of them the same, the second for an amount $\left(\mathrm{Q}_{1}\right)$ the fifth for another amount $\left(\mathrm{Q}_{5}\right)$, and the last payment for another amount $\left(\mathrm{Q}_{10}\right)$ the remaining 7 payments for similar amounts: $P_{N 2}, P_{N 3}, P_{N 4}, P_{N 6}, P_{N 7}, P_{N 8}, P_{N 9}$ (which is the same as $Y{ }_{2}, Y^{\prime \prime}, Y^{\prime \prime}, Y^{\prime \prime}, Y{ }_{7}, A N D$ "8, $\left.A N D{ }_{9}\right)$.

The original debt is backed by 7 documents with different amounts and maturity dates: three of them have already expired, one on the focal date proposed for restructuring and the remaining three with maturities after the focal date. The proposal agrees to cover an amount that represents the transaction costs in favor of the creditor, as well as the use of the effective rate to update the expired documents and the real rate for the documents that are discounted at the focal date. In this way, the original proposal of García-Santillán (2019) is taken, which seeks to demonstrate:

$$
Y_{1 . . . j}=\frac{V_{O D}}{V_{N S P}} \quad \text { and } \quad Y_{1 \ldots j}^{\prime \prime}=\frac{V_{O D_{\text {afjisted }}}}{V_{N S P_{\text {aljisuted }}}}
$$

Thus, the original debt is initially valued with the effective rate and the actual rate, according to the following expression:

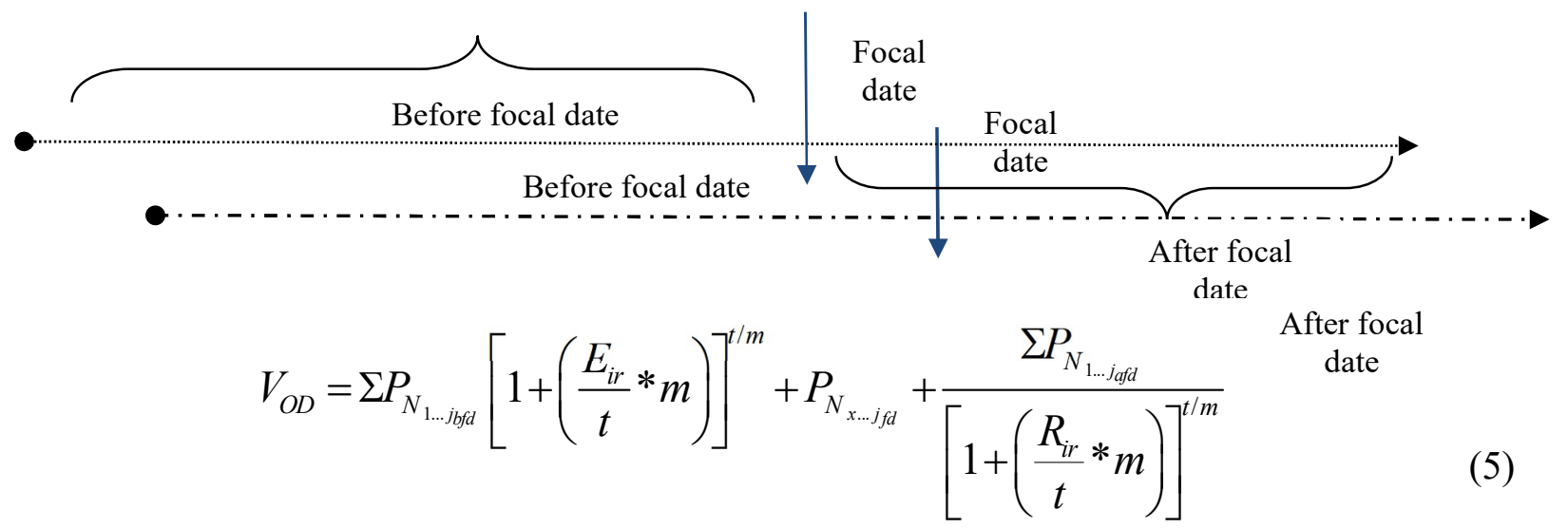

Then the new payment scheme is valued. At this point the number of payments of the new debt is established. For this example, it will be 10 new payments, so the values of each promissory note are replaced by $X$, which represents the unit (1) using equation $(5.2 ; 5.2 .1$ or 5.2.2) simplified: 


$$
\begin{gathered}
V_{N S P}=X_{f d}+\sum_{1 \ldots j}^{a f d} \frac{X_{n 1_{a f d}}}{\left[1+\left(\frac{i_{d}}{m}\right)\right]^{t / m}}+\ldots+\frac{X_{n j_{a f d}}}{\left[1+\left(\frac{i_{d}}{m}\right)\right]^{t / m}} \\
V_{N S P}=1_{f d}+\sum_{1 \ldots j}^{a f d} \frac{1_{n 1_{a f d}}\left[1+\left(\frac{i_{d}}{m}\right)\right]^{t / m}}{[}+\ldots+\frac{1_{n j_{a f d}}}{\left[1+\left(\frac{i_{d}}{m}\right)\right]^{t / m}} \\
\left.\left.V_{N S P}=1_{f d}+\sum_{1 \ldots j}^{a f d} \frac{1_{n 1_{a f d}}}{\left[1+\left(\frac{R_{i r} *}{t} *\right]_{n j_{a f d}}\right.}\right)\right]^{t / m}+\ldots+\frac{\left.\left.R_{i r} * m\right)\right]^{t / m}}{\left[1+\left(\frac{R^{\prime}}{t} m\right.\right.}
\end{gathered}
$$

In this way the equation model is run to solve scenario 3 which sought, firstly, to revalue the original debt, then to integrate the percentage of prorated transaction costs in each of the revalued promissory notes. Finally, a new payment scheme is proposed, considering that in three of them, there was already a fixed amount at the beginning. Thus, the equation was modified in the numerator, leaving it as follows:

From the equation $Y_{1 \ldots j}=V_{O D} / V_{N S P}$ it was transformed to $Y_{1 \ldots j}^{\prime \prime}=V_{O D_{\text {adjusted }}} / V_{N S P_{\text {adjusted }}}$, so that in its reduced form it is displayed as follows:

$$
Y_{2,3,4,6,7,8,9}^{\prime \prime}=\frac{\left(\Sigma Q_{1}+Q_{2}+Q_{10}\right)-\left(V_{\text {OD }}{ }_{\text {ajjusted }}=\Sigma P_{N 2 \ldots 4}, P_{N 6 \ldots 9}\right)}{V_{N S P_{\text {adjusted }}}}
$$

The timeline of the new payment scheme is:

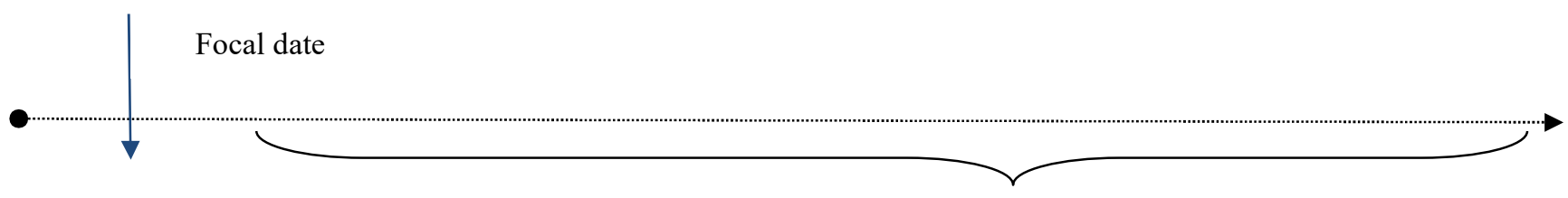

After focal date

How to view this hypothetical case? As mentioned, first the original debt must be revalued. For this, we start from equation 5, and present the model with the 7 documents: three that have expired, one expires on the proposed focal date and the remaining three with maturities after that focal date. In both cases, the effective rate and the real rate are considered. In addition, a percentage of transaction costs is stipulated in favor of the creditor.

$$
\begin{aligned}
& V_{O D}=\sum P_{N 1_{b f d}}\left[1+\left(\frac{E_{i r}}{t} * m\right)\right]^{t / m}+P_{N 2_{b f d}}\left[1+\left(\frac{E_{i r}}{t} * m\right)\right]^{t / m}+P_{N 3_{b f d}}\left[1+\left(\frac{E_{i r}}{t} * m\right)\right]^{t / m} \ldots+ \\
& \ldots+P_{N 4_{f d}}+\sum \frac{P_{N 5_{a f d}}}{\left[1+\left(\frac{\left.R_{i r} * m\right)}{t} * m\right.\right.}+\frac{\left.P_{N 6_{a f d}}\right]^{t / m}}{\left[1+\left(\frac{\left.R_{i r} * m\right)}{t} * m\right)\right.}+\frac{\left.P_{N 7_{a f d}}\right]^{t / m}}{\left[1+\left(\frac{\left.\left.R_{i r} * m\right)\right]^{t / m}}{t}\right.\right.}
\end{aligned}
$$


Once the debt has been revalued, with the data, $V_{O D}$ equation 10 is now used to prorate the amount of transaction costs, in each of the promissory notes $\left(P_{N 1 \ldots j}\right)$

$$
\begin{aligned}
& V_{O D_{a d j i s t e d}}=\sum_{1 \ldots . j}^{b f d}\left[\left(\frac{P_{N 1_{b f d}}^{\prime \prime}}{V_{O D}}\right) *\left(V_{O D} * i_{t c e}\right)\right]+\left[\left(\frac{P_{N 2_{b f d}}^{\prime \prime}}{V_{O D}}\right) *\left(V_{O D} * i_{t c e}\right)\right]+\left[\left(\frac{P_{N 3_{b f d}}^{\prime \prime}}{V_{O D}}\right) *\left(V_{O D} * i_{t c e}\right)\right]+\left[\left(\frac{P_{N 4_{f d d}}^{\prime \prime}}{V_{O D}}\right) *\left(V_{O D} * i_{t c e}\right)\right]+\ldots
\end{aligned}
$$

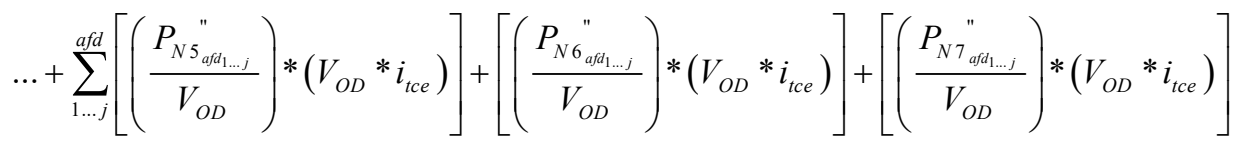

In the general equation, the 10 payments after the focal date with which it is intended to restructure the new payment scheme are integrated into the equation as follows:

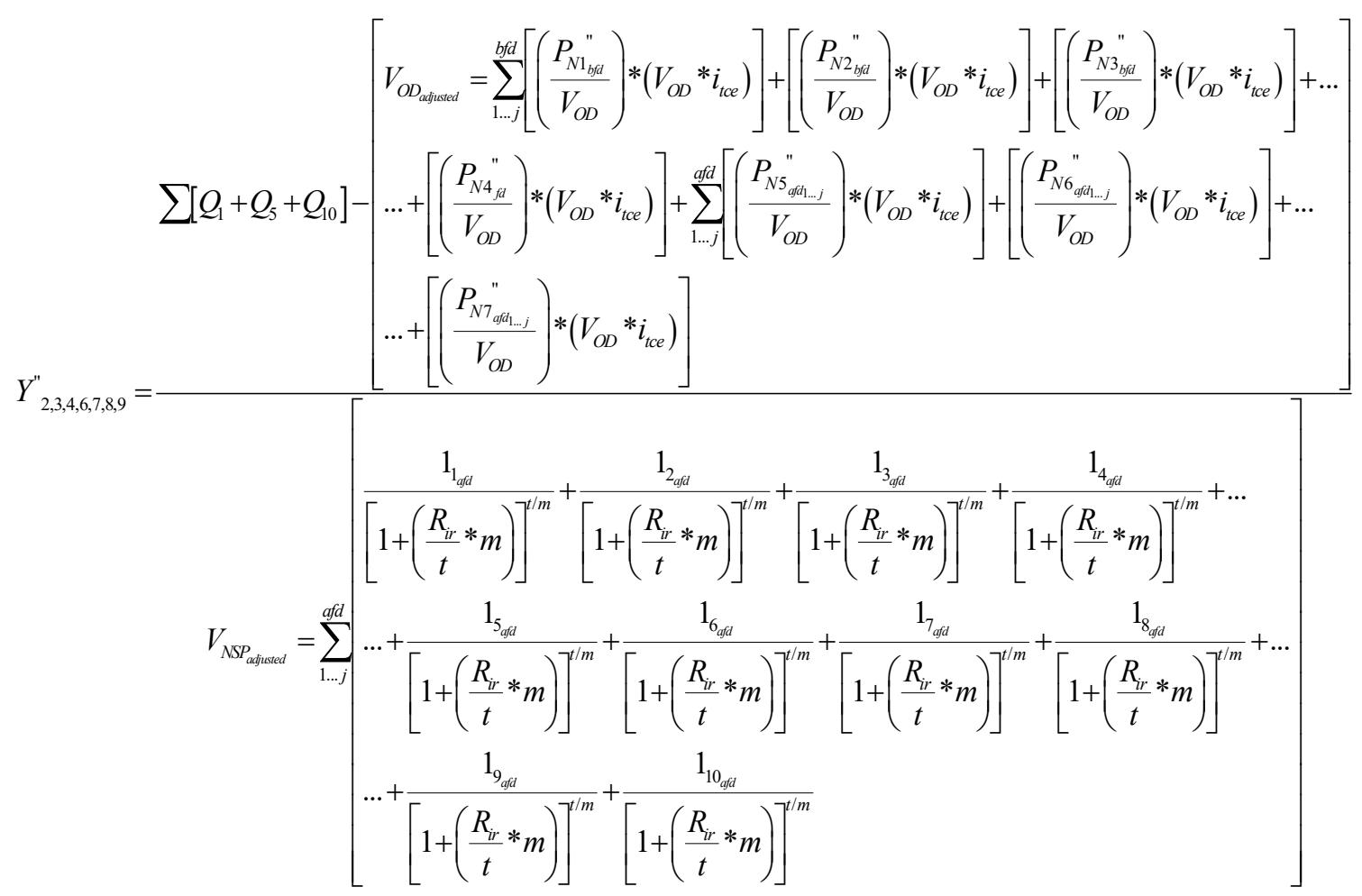

\section{Development of the mathematical model in three hypothetical scenarios}

To visualize the three moments of the previously exposed scenarios, the verification of each hypothetical scenario is developed below in order to be able to visualize the financial behavior, through the use of a spreadsheet designed in Excel format. For this, in each scenario the types of rate to be used, the compounding periods, amounts, days of maturity and focal date are all hypothetically described to develop the calculations.

Scenario 1: The 10 documents have expired and are restructured in a similar number of equal payments every 30 days, all after a focal date, with conversion of the debt from dollars to Mexican pesos with a spot exchange rate of $\$ 20.50$ per dollar and $2.5 \%$ of transaction costs according to the data in table 2 : 
Table 2. Data for develop scenario 1

\begin{tabular}{|c|c|c|c|c|c|}
\hline $\begin{array}{c}\text { Promissory } \\
\text { note }\end{array}$ & $\begin{array}{c}\text { Expired / not } \\
\text { expired }\end{array}$ & Year & $\begin{array}{c}\text { Days to focal } \\
\text { date }\end{array}$ & $\begin{array}{l}\text { Interest } \\
\text { rate }\end{array}$ & Amounts (thousand dls.) \\
\hline \multicolumn{6}{|c|}{ Original debt to valuation } \\
\hline 1 & bfd & 2019 & 450 & 10.8 & $\$ 150.00$ \\
\hline 2 & $b f d$ & 2019 & 370 & 10.8 & $\$ 120.00$ \\
\hline 3 & $b f d$ & 2020 & 290 & 10.8 & $\$ 90.00$ \\
\hline 4 & $b f d$ & 2020 & 260 & 10.8 & $\$ 80.00$ \\
\hline 5 & $b f d$ & 2020 & 230 & 10.8 & $\$ 110.00$ \\
\hline 6 & $b f d$ & 2020 & 190 & 10.8 & $\$ 118.00$ \\
\hline 7 & bfd & 2020 & 120 & 10.8 & $\$ 63.00$ \\
\hline 8 & $b f d$ & 2020 & 85 & 10.8 & $\$ 75.00$ \\
\hline 9 & bfd & 2020 & 50 & 10.8 & $\$ 60.00$ \\
\hline 10 & bfd & 2020 & 15 & 10.8 & $\$ 45.00$ \\
\hline \multicolumn{6}{|c|}{ New scheme of payment } \\
\hline $\begin{array}{l}10 \text { equal } \\
\text { payments }\end{array}$ & afd & $2020-2021$ & every 30 days & 5.6 & Equal payments \\
\hline
\end{tabular}

Table 3. Valuation of the original debt scenario 1

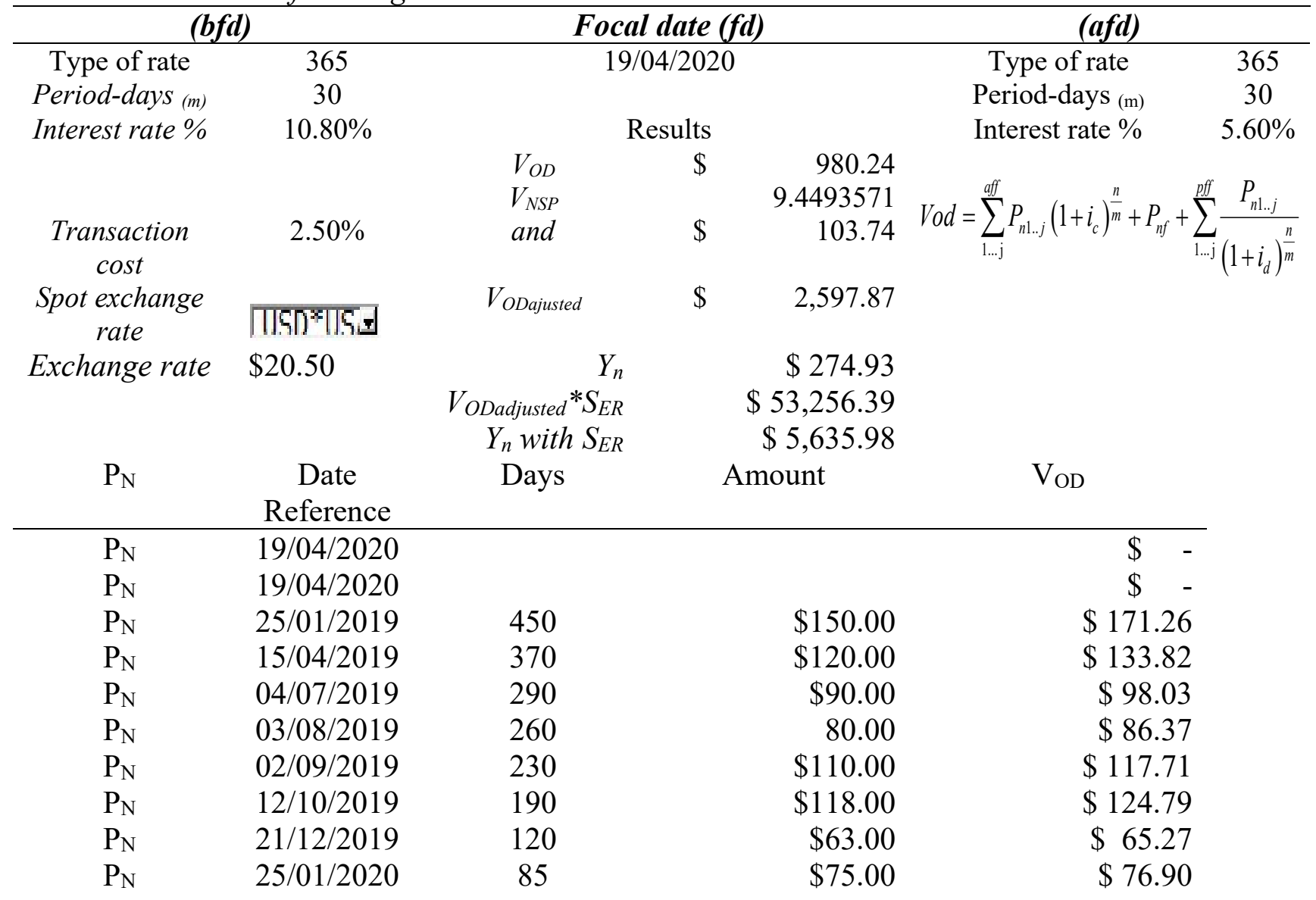




$\begin{array}{cccccc}\mathrm{P}_{\mathrm{N}} & 29 / 02 / 2020 & 50 & \$ 60.00 & \$ 60.89 \\ \mathrm{P}_{\mathrm{N}}(b f d) & 04 / 04 / 2020 & 15 & \$ 45.00 & \$ 45.20 & (b f d) \\ \text { Focal date }(f d) & 19 / 04 / 2020 & 0 & & \$- & (f d) \\ \mathrm{P}_{\mathrm{N}} & 19 / 04 / 2020 & & & \$- & (a f d) \\ \mathrm{P}_{\mathrm{N}} & 19 / 04 / 2020 & & & \$- & \$ 980.24\end{array}$

New payment scheme proposed for scenario $1 V_{N S P}=\sum_{1 \ldots j}^{b f d} X_{1}\left(1+i_{c}\right)^{n / m}+X_{f d}+\sum_{1 \ldots j}^{a f d} X_{1 \ldots j} /\left(1+i_{d}\right)^{n / m}$

Table 3.b Coefficients for the new payment scheme proposed for scenario 1

\begin{tabular}{|c|c|c|c|c|}
\hline & $\boldsymbol{P}_{N}$ & Value $X_{1 \ldots j}$ & Days & $V_{N S P}$ \\
\hline$(b f d)$ & PN 1 & & & \\
\hline \multirow{10}{*}{ (afd) } & PN 2 & 1 & 30 & 0.9954183 \\
\hline & $P_{N} 3$ & 1 & 90 & 0.9863179 \\
\hline & $P_{N} 4$ & 1 & 120 & 0.9817990 \\
\hline & PN 5 & 1 & 150 & 0.9773007 \\
\hline & $\mathbf{P}_{N} 6$ & 1 & 180 & 0.9728230 \\
\hline & $P_{N} 7$ & 1 & 210 & 0.9683659 \\
\hline & $\mathbf{P N}_{\mathbf{N}} 8$ & 1 & 240 & 0.9639292 \\
\hline & $P_{N} 9$ & 1 & 270 & 0.6574286 \\
\hline & $\mathbf{P}_{\mathrm{N}} 10$ & 1 & 300 & 0.9551167 \\
\hline & & & $V n s p$ & 9.449357 \\
\hline
\end{tabular}

Table 3.c Value of each promissory note renegotiated to Mexican pesos

\begin{tabular}{|c|c|c|c|}
\hline \multicolumn{4}{|c|}{ Cost for each renegotiated payment. } \\
\hline$P N$ & $V_{O D}$ & VoDadjusted & \multirow{5}{*}{$\sum_{1 . . j}^{a f f}\left[P_{n 1}\left[\left(\frac{P_{n 1}}{V o d}\right)\left(\operatorname{Vod}^{*} i_{t e}\right)\right.\right.$} \\
\hline$P N$ & $\$ 171.26$ & $\$ 733.27$ & \\
\hline$P N$ & 133.82 & 447.69 & \\
\hline$P N$ & 98.03 & 240.23 & \\
\hline$P N$ & 86.37 & 186.49 & \\
\hline$P N$ & 117.71 & 346.40 & Vnsp \\
\hline$P N$ & 124.79 & 389.33 & \\
\hline$P N$ & 65.27 & 66.90 & \multirow[b]{4}{*}{$\operatorname{Vod}_{\text {adjusted }} * S_{E R}$} \\
\hline$P N$ & 76.90 & 78.82 & \\
\hline$P N$ & 60.89 & 62.41 & \\
\hline$P N$ & 45.20 & 46.33 & \\
\hline \multirow[t]{5}{*}{ Focal date (fd) } & $\$-$ & $\$-$ & \multirow{4}{*}{$\overline{V n s p}$} \\
\hline & VODAdjusted & $\$ 2,597.87$ & \\
\hline & $V_{N S P}$ & 9.8887228 & \\
\hline & $Y^{n}$ & $\$ 262.71$ & \\
\hline & \multicolumn{3}{|c|}{ Calculus with the Sport exchange rate } \\
\hline$V_{\text {ODadjusted }}$ & $\$ 2,597.87$ & $V_{O D A d j u s t e d}{ }^{*} S_{E R}$ & $\$ 53,256.39$ \\
\hline$S_{E R}$ & $\$ 20.50$ & $Y_{n}$ with $S_{E R}$ & $\$ 5,385.57$ \\
\hline$V_{N S P}$ & $\$ 9.89$ & & \\
\hline
\end{tabular}




\section{For scenario 2.}

In this scenario, there are no documents that have expired, but the debtor requests a restructuring in the following terms: one payment on the focal date and 9 subsequent equal payments after the focal date (every 30 days). For the revaluation of the original debt, the same data is taken from the 10 documents used in scenario one, inverting the days to expire from lowest to highest, with conversion of the debt from dollars to Mexican pesos with a spot exchange rate of $\$ 20.50$ per dollar and $2.5 \%$ of transaction costs according to the data in table 4 :

Table 4. Data for develop scenario 2

\begin{tabular}{|c|c|c|c|c|c|}
\hline $\begin{array}{l}\text { Promissory } \\
\text { note }\end{array}$ & $\begin{array}{l}\text { Expired / not } \\
\text { expired }\end{array}$ & Year & $\begin{array}{c}\text { Days to focal } \\
\text { date }\end{array}$ & $\begin{array}{l}\text { Interest } \\
\text { rate }\end{array}$ & $\begin{array}{c}\text { Amounts (thousand } \\
\text { dls.) }\end{array}$ \\
\hline \multicolumn{6}{|c|}{ Original debt to valuation } \\
\hline 1 & afd & 2019 & 15 & 10.8 & $\$ 150.00$ \\
\hline 2 & afd & 2020 & 50 & 10.8 & $\$ 120.00$ \\
\hline 3 & afd & 2020 & 85 & 10.8 & $\$ 90.00$ \\
\hline 4 & afd & 2020 & 120 & 10.8 & $\$ 80.00$ \\
\hline 5 & afd & 2020 & 190 & 10.8 & $\$ 110.00$ \\
\hline 6 & afd & 2020 & 230 & 10.8 & $\$ 118.00$ \\
\hline 7 & afd & 2020 & 260 & 10.8 & $\$ 63.00$ \\
\hline 8 & afd & 2020 & 290 & 10.8 & $\$ 75.00$ \\
\hline 9 & afd & 2020 & 370 & 10.8 & $\$ 60.00$ \\
\hline 10 & afd & 2020 & 450 & 10.8 & $\$ 45.00$ \\
\hline \multicolumn{6}{|c|}{ New scheme of payment } \\
\hline 1 & $f d$ & 219 & 0 & 5.6 & Equal payment \\
\hline $\begin{array}{c}9 \text { equal } \\
\text { payments }\end{array}$ & afd & $220-221$ & $\begin{array}{c}\text { Every } 30 \\
\text { days }\end{array}$ & 5.6 & Equal payments \\
\hline
\end{tabular}

*bfd (before focal date), afd (after focal date, fd (focal date)

*capitalizations every 30 days

Table 5. Valuation of the original debt scenario 2

\begin{tabular}{|c|c|c|c|c|c|}
\hline \multicolumn{2}{|c|}{$(b f d)$} & \multicolumn{2}{|c|}{ Focal date (fd) } & \multicolumn{2}{|l|}{$(a f d)$} \\
\hline Type of rate & 365 & & 2020 & Type of rate & 365 \\
\hline Period-days (m) & 30 & & & Period-days (m) & 30 \\
\hline Interest rate $\%$ & $10.80 \%$ & & & Interest rate \% & $5.60 \%$ \\
\hline & 0.0088767 & $V_{O D}$ & $\$ 887.87$ & $i_{d}$ & 0.0046027 \\
\hline Transaction cost & $2.50 \%$ & $V_{N S P}$ & 9.6916309 & $Y_{n}$ & $\$ 152.23$ \\
\hline Spot exchange rate & 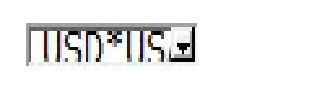 & and & $\$ 91.61$ & $\begin{array}{r}V_{\text {ODadjusted }} * S_{E R} \\
Y_{n} \text { with } S_{E R}\end{array}$ & $\$ 30,245.02$ \\
\hline Exchange rate & $\$ 20.50$ & VoDadjusted & $\$ 1,475.37$ & $V_{\text {ODajusted }}$ & $\$ 3,120.74$ \\
\hline $\mathrm{P}_{\mathrm{N}}$ & Date Reference & Days & Amount & $\mathrm{V}_{\mathrm{OD}}$ & \\
\hline $\mathrm{P}_{\mathrm{N}}$ & $19 / 11 / 2020$ & 0 & 0 & \$- & (bfd) \\
\hline Focal date (fd) & $19 / 11 / 2020$ & 0 & & \$- & $(\mathrm{fd})$ \\
\hline $\mathrm{P}_{\mathrm{N}}$ & $04 / 12 / 2020$ & 15 & $\$ 150.00$ & $\$ 149.66$ & (afd) \\
\hline $\mathrm{P}_{\mathrm{N}}$ & $08 / 01 / 2021$ & 50 & $\$ 120.00$ & $\$ 119.09$ & \\
\hline $\mathrm{P}_{\mathrm{N}}$ & $12 / 02 / 2021$ & 85 & $\$ 90.00$ & $\$ 88.84$ & \\
\hline $\mathrm{P}_{\mathrm{N}}$ & $19 / 03 / 2021$ & 120 & $\$ 80.00$ & $\$ 78.54$ & \\
\hline
\end{tabular}




$\begin{array}{rrrrr}\mathrm{P}_{\mathrm{N}} & 28 / 05 / 2021 & 190 & \$ 110.00 & \$ 106.85 \\ \mathrm{P}_{\mathrm{N}} & 07 / 07 / 2021 & 230 & \$ 118.00 & \$ 113.92 \\ \mathrm{P}_{\mathrm{N}} & 06 / 08 / 2021 & 260 & \$ 63.00 & \$ 60.54 \\ \mathrm{P}_{\mathrm{N}} & 05 / 09 / 2021 & 290 & \$ 75.00 & \$ 71.74 \\ \mathrm{P}_{\mathrm{N}} & 24 / 11 / 2021 & 370 & \$ 60.00 & \$ 56.70 \\ \mathrm{P}_{\mathrm{N}} & 12 / 02 / 2022 & 450 & \$ 45.00 & \$ 42.00 \\ & & & \mathrm{~V}_{O D} & 887.87\end{array}$

New payment scheme proposed for scenario $2 \quad V n s p=\sum^{a f f} X_{1}\left(1+i_{c}\right)^{\frac{n}{m}}+x_{f f}+\sum^{p f f} \frac{X_{1 \ldots j}}{\left(1+i_{d}\right)^{\frac{n}{m}}}$

Table 5.b Coefficients for the new payment scheme proposed for scenario 2

\begin{tabular}{lcccr}
\hline & $\boldsymbol{P}_{\boldsymbol{N}}$ & Value $\boldsymbol{X}_{\boldsymbol{1} \ldots \boldsymbol{j}}$ & Days & \multicolumn{1}{c}{$\boldsymbol{V}_{\boldsymbol{N} \text { SP }}$} \\
\hline (bfd) & 0 & 0 & 0 & 0 \\
(afd) & $\mathrm{P}_{\mathrm{N}} 1$ & 1 & 15 & 0.9977065 \\
& $\mathrm{P}_{\mathrm{N}} 2$ & 1 & 50 & 0.9923756 \\
& $\mathrm{P}_{\mathrm{N}} 3$ & 1 & 85 & 0.9870731 \\
& $\mathrm{P}_{\mathrm{N}} 4$ & 1 & 120 & 0.981799 \\
& $\mathrm{P}_{\mathrm{N}} 5$ & 1 & 190 & 0.9713351 \\
& $\mathrm{P}_{\mathrm{N}} 6$ & 1 & 230 & 0.9654058 \\
& $\mathrm{P}_{\mathrm{N}} 7$ & 1 & 260 & 0.9609827 \\
& $\mathrm{P}_{\mathrm{N}} 8$ & 1 & 290 & 0.9565798 \\
& $\mathrm{P}_{\mathrm{N}} 9$ & 1 & 370 & 0.9449371 \\
& $\mathrm{P}_{\mathrm{N}} 10$ & 1 & 450 & 0.9334362 \\
& & & $V_{N S P}$ & 9.691631 \\
\hline
\end{tabular}

Table 5.c Value of each promissory note renegotiated to Mexican pesos

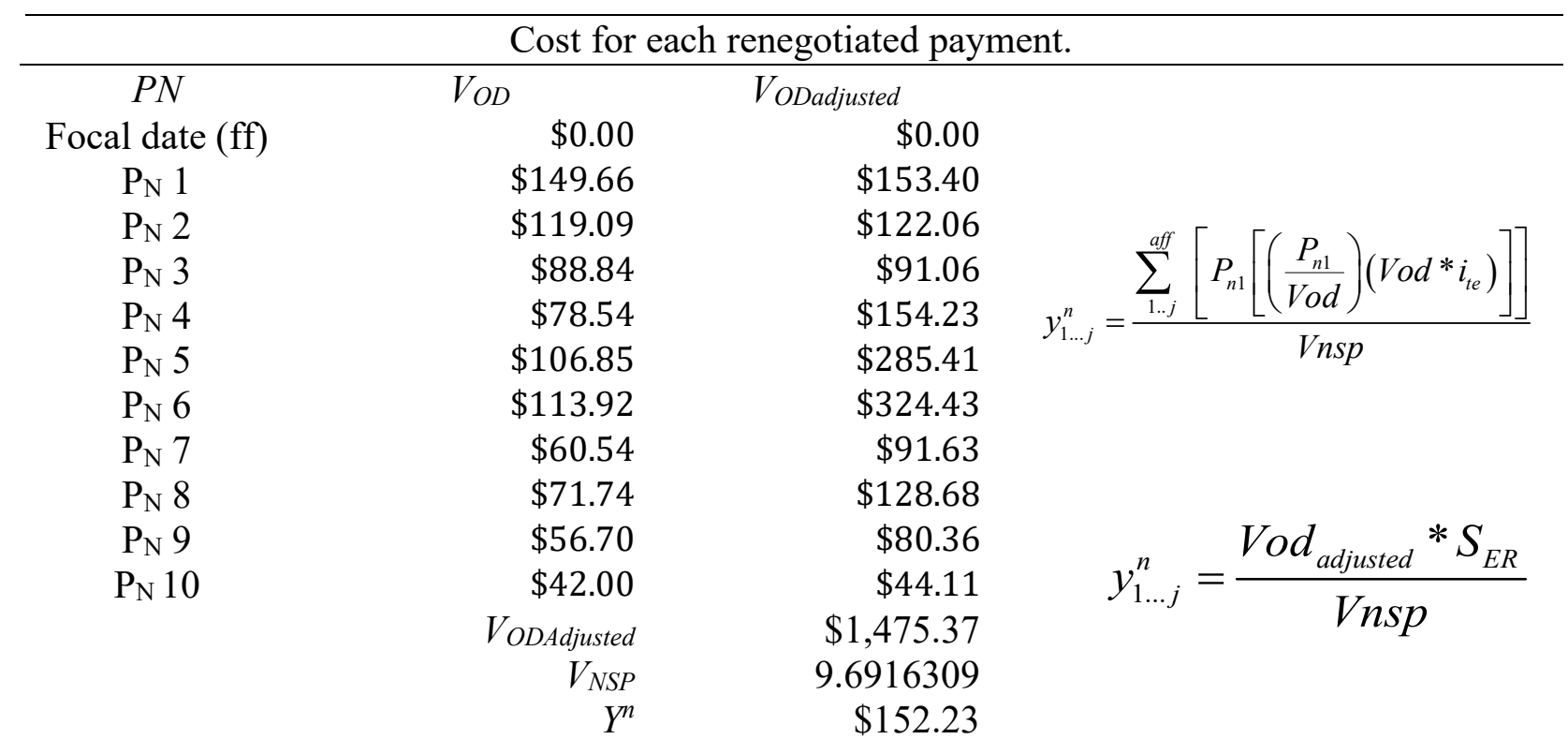


Calculus with the Sport exchange rate

$$
\begin{array}{rr}
\text { Vod }_{\text {Adjusted }} & \$ 1,475.37 \\
S_{E R} & \$ 20.50 \\
V_{N S P} & 9.69
\end{array}
$$

$V_{\text {ODAdjusted }}{ } S_{E R}$

$Y_{n}$ with $S_{E R}$
$\$ 30,245.02$

$\$ 3,120.74$

\section{For scenario 3.}

In this hypothetical scenario, not all payments are equal in the new payment scheme. They are as follows: 10 payments after the focal date, 7 of them equal, the second for an amount $\left(\mathrm{Q}_{1}\right)$ the fifth for another amount $\left(\mathrm{Q}_{5}\right)$, and the last payment for another amount $\left(\mathrm{Q}_{10}\right)$. The remaining 7 payments for similar amounts: $\mathrm{P}_{\mathrm{N} 2}, \mathrm{P}_{\mathrm{N} 3}, \mathrm{P}_{\mathrm{N} 4}, \mathrm{P}_{\mathrm{N} 6}, \mathrm{P}_{\mathrm{N} 7}, \mathrm{P}_{\mathrm{N} 8}, \mathrm{P}_{\mathrm{N} 9}$ (which is the same as $Y^{\prime \prime} 2, Y^{\prime \prime}{ }_{3}$, $\left.Y_{4}, Y_{6}{ }_{6}, Y_{7}, Y_{8}, Y^{\prime \prime}\right)$. Each payment is made every 30 days.

The original debt consists of 7 documents with different amounts and maturity dates: three of them have already expired, one on the focal date that was proposed for restructuring and the remaining three with maturities after the focal date. The calculation is made by converting the debt from dollars to Mexican pesos with a spot exchange rate of $\$ 20.50$ per dollar and $2.5 \%$ of transaction costs, and the same interest rates (10.8\% payments due and $5.6 \%$ not yet due).

Table 6. Data for develop scenario 3

\begin{tabular}{cccccr}
\hline $\begin{array}{c}\text { Promissory } \\
\text { note }\end{array}$ & $\begin{array}{c}\text { Expired/not } \\
\text { expired }\end{array}$ & Year & $\begin{array}{c}\text { Days to focal } \\
\text { date }\end{array}$ & $\begin{array}{c}\text { Interest } \\
\text { rate }\end{array}$ & $\begin{array}{c}\text { Amounts (thousand } \\
\text { dls. }\end{array}$ \\
\hline 1 & \multicolumn{3}{c}{ Original debt to valuation } \\
2 & bfd & 2019 & 90 & 10.8 & $\$ 150.00$ \\
3 & bfd & 2019 & 60 & 10.8 & $\$ 120.00$ \\
4 & bfd & 2020 & 30 & 10.8 & $\$ 90.00$ \\
5 & fd & 2020 & 0 & 10.8 & $\$ 80.00$ \\
6 & afd & 2020 & 30 & 10.8 & $\$ 110.00$ \\
7 & afd & 2020 & 75 & 10.8 & $\$ 118.00$ \\
& afd & 2020 & 120 & 10.8 & $\$ 63.00$ \\
\hline 1 & & $N e w$ scheme of payment & & Equal payment \\
2 & afd & 2021 & 30 & 5.6 & $\$ 45.00$ \\
3 & afd & 2021 & 60 & 5.6 & Equal payment \\
4 & afd & 2021 & 90 & 5.6 & Equal payment \\
5 & afd & 2021 & 120 & 5.6 & $\$ 35.00$ \\
6 & afd & 2021 & 150 & 5.6 & Equal payment \\
7 & afd & 2021 & 180 & 5.6 & Equal payment \\
8 & afd & 2021 & 210 & 5.6 & Equal payment \\
9 & afd & 2021 & 240 & 5.6 & Equal payment \\
10 & afd & 2021 & 270 & 5.6 & $\$ 25.00$ \\
\hline
\end{tabular}

*bfd (before focal date), afd (after focal date, fd (focal date)

*capitalizations every 30 days 
Table 7. Valuation of the original debt scenario 3

\begin{tabular}{|c|c|c|c|c|c|}
\hline \multicolumn{2}{|c|}{$(b f d)$} & \multicolumn{2}{|c|}{ Focal date (fd) } & \multicolumn{2}{|l|}{ (afd) } \\
\hline Type of rate & 365 & \multicolumn{2}{|c|}{ 19/11/2020 } & Type of rate & 365 \\
\hline Period-days (m) & 30 & & & Period-days (m) & 30 \\
\hline Interest rate \% & $10.80 \%$ & Resultac & & Interest rate $\%$ & $5.60 \%$ \\
\hline$i_{c}$ & 0.0088767 & $V_{O D}$ & $\$ 734.97$ & \multirow{7}{*}{\multicolumn{2}{|c|}{$\operatorname{Vod}=\sum_{1 . . . j}^{a f f} P_{n 1 . j}\left(1+i_{c}\right)^{\frac{n}{m}}+P_{n f}+\sum_{1 . . \mathrm{j}}^{p f f} \frac{P_{n 1 . . j}}{\left(1+i_{d}\right)^{\frac{n}{m}}}$}} \\
\hline & & $V_{N S P}$ & 9.7514412 & & \\
\hline & & and & $\$ 75.37$ & & \\
\hline Transaction cost & $2.50 \%$ & VoDadjusted & $\$ 753.35$ & & \\
\hline $\begin{array}{c}\text { Spot exchange } \\
\text { rate }\end{array}$ & $\left.\left.\prod \mid S\right\rceil\right)^{*} \mid \mathrm{S}$. & $Y_{n}$ & $\$ 77.25$ & & \\
\hline \multirow[t]{2}{*}{ Exchange rate } & \multirow[t]{2}{*}{$\$ 20.50$} & $V_{\text {ODadjusted }} * S_{E R}$ & $\$ 15,443.58$ & & \\
\hline & & $Y_{n}$ with $S_{E R}$ & $\$ 1,583.72$ & & \\
\hline $\mathrm{P}_{\mathrm{N}}$ & $\begin{array}{c}\text { Date } \\
\text { Reference }\end{array}$ & Days & Amount & $\mathrm{V}_{\mathrm{OD}}$ & \\
\hline $\mathrm{P}_{\mathrm{N}}$ & $19 / 11 / 2020$ & & & $\$ 0.00$ & $(b f d)$ \\
\hline $\mathrm{P}_{\mathrm{N}}$ & $21 / 08 / 2020$ & 90 & $\$ 150.00$ & $\$ 154.03$ & $(b f d)$ \\
\hline $\mathrm{P}_{\mathrm{N}}$ & $20 / 09 / 2020$ & 60 & $\$ 120.00$ & $\$ 122.14$ & $(b f d)$ \\
\hline $\mathrm{P}_{\mathrm{N}}$ & $20 / 10 / 2020$ & 30 & $\$ 90.00$ & $\$ 90.80$ & $(b f d)$ \\
\hline Focal date (fd) & $19 / 11 / 2020$ & 0 & $\$ 80.00$ & $\$ 80.00$ & $(f d)$ \\
\hline $\mathrm{P}_{\mathrm{N}}$ & $19 / 12 / 2020$ & 30 & $\$ 110.00$ & $\$ 109.50$ & $(a f d)$ \\
\hline $\mathrm{P}_{\mathrm{N}}$ & $02 / 02 / 2021$ & 75 & $\$ 118.00$ & $\$ 116.65$ & (afd) \\
\hline $\mathrm{P}_{\mathrm{N}}$ & $19 / 03 / 2021$ & 120 & $\$ 63.00$ & $\$ 61.85$ & $(a f d)$ \\
\hline $\mathrm{P}_{\mathrm{N}}$ & $19 / 11 / 2020$ & & & $\$ 0.00$ & $(a f d)$ \\
\hline & & & $V_{O D}$ & 734.97 & \\
\hline
\end{tabular}

Table 7.b Coefficients for the new payment scheme proposed for scenario 3

\begin{tabular}{|c|c|c|c|c|}
\hline$P_{N}$ & Value $X_{1 \ldots j}$ & Days & $V_{N S P}$ & $P_{N}$ \\
\hline$(b f d)$ & - & - & - & 0 \\
\hline \multirow[t]{11}{*}{ (afd) } & $P_{N} 1$ & 1 & 30 & 0.995418 \\
\hline & $P_{N} 2$ & 1 & 60 & 0.990857 \\
\hline & $P_{N} 3$ & 1 & 90 & 0.986317 \\
\hline & $P_{N} 4$ & 1 & 120 & 0.981799 \\
\hline & $P_{N} 5$ & 1 & 150 & 0.977300 \\
\hline & $P_{N} 6$ & 1 & 180 & 0.972823 \\
\hline & $P_{N} 7$ & 1 & 210 & 0.968365 \\
\hline & $P_{N} 8$ & 1 & 240 & 0.963929 \\
\hline & $P_{N} 9$ & 1 & 270 & 0.959512 \\
\hline & $\mathrm{P}_{\mathrm{N}} 10$ & 1 & 300 & 0.955116 \\
\hline & & & $V n s p$ & 9.751441 \\
\hline
\end{tabular}


Table 7.c Value of each promissory note renegotiated to Mexican pesos

\begin{tabular}{|c|c|c|c|c|}
\hline \multicolumn{5}{|c|}{ Cost for each renegotiated payment } \\
\hline $\mathrm{P}_{\mathrm{N}}$ & $\mathrm{V}_{\mathrm{OD}}$ & VoDadjusted & \multirow{14}{*}{$y_{1 \ldots j}^{n}=$} & \\
\hline $\mathrm{P}_{\mathrm{N}}$ & $\$ 0$ & $\$ 0.00$ & & \\
\hline $\mathrm{P}_{\mathrm{N}}$ & $\$ 0$ & $\$ 0.00$ & & $\left(P_{n 1}\right)\left(\operatorname{Vod}_{* i}\right)$ \\
\hline $\mathrm{P}_{\mathrm{N}}$ & $\$ 154.03$ & $\$ 157.88$ & & $\left(\frac{\operatorname{lod}_{1}}{\operatorname{Vod}}\right)\left(\operatorname{Vod}^{*} l_{t e}\right)$ \\
\hline $\mathrm{P}_{\mathrm{N}}$ & $\$ 122.14$ & $\$ 125.19$ & & $V n s n$ \\
\hline $\mathrm{P}_{\mathrm{N}}$ & $\$ 90.80$ & $\$ 93.07$ & & insp \\
\hline Focal date (fd) & $\$ 80.00$ & $\$ 82.00$ & & \\
\hline $\mathrm{P}_{\mathrm{N}}$ & $\$ 109.50$ & $\$ 112.23$ & & \\
\hline $\mathrm{P}_{\mathrm{N}}$ & $\$ 116.65$ & $\$ 119.57$ & & \\
\hline $\mathrm{P}_{\mathrm{N}}$ & $\$ 61.85$ & $\$ 63.40$ & & \\
\hline \multirow[t]{4}{*}{$\mathrm{P}_{\mathrm{N}}$} & $\$ 0$ & $\$ 0.00$ & & \\
\hline & VoDadjusted & $\$ 753.35$ & & \\
\hline & $/ V_{N S P}$ & 9.7514412 & & \\
\hline & $Y^{n}$ & $\$ 77.25$ & & \\
\hline
\end{tabular}

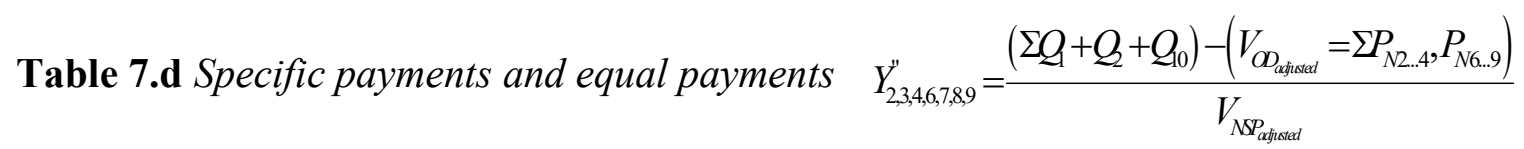

\begin{tabular}{|c|c|c|c|c|}
\hline & $\mathbf{P}_{\mathbf{N}}$ & Value & $Y_{n}$ with $S_{E R}$ & VoDadjusted $* S_{E R}$ \\
\hline \multicolumn{5}{|l|}{ (bfd) } \\
\hline (afd) & $\mathrm{P}_{\mathrm{N}} 1$ & $\$ 77.25$ & $\$ 20.50$ & $\$ 1,583.72$ \\
\hline (afd) & $\mathrm{P}_{\mathrm{N}} 2$ & $\$ 45.00$ & $\$ 20.50$ & $\$ 922.50$ \\
\hline (afd) & $\mathrm{P}_{\mathrm{N}} 3$ & $\$ 77.25$ & $\$ 20.50$ & $\$ 1,583.72$ \\
\hline (afd) & $\mathrm{P}_{\mathrm{N}} 4$ & $\$ 77.25$ & $\$ 20.50$ & $\$ 1,583.72$ \\
\hline (afd) & $\mathrm{P}_{\mathrm{N}} 5$ & $\$ 35.00$ & $\$ 20.50$ & $\$ 717.50$ \\
\hline (afd) & $\mathrm{P}_{\mathrm{N}} 6$ & $\$ 77.25$ & $\$ 20.50$ & $\$ 1,583.72$ \\
\hline (afd) & $\mathrm{P}_{\mathrm{N}} 7$ & $\$ 77.25$ & $\$ 20.50$ & $\$ 1,583.72$ \\
\hline (afd) & $\mathrm{P}_{\mathrm{N}} 8$ & $\$ 77.25$ & $\$ 20.50$ & $\$ 1,583.72$ \\
\hline (afd) & $\mathrm{P}_{\mathrm{N}} 9$ & $\$ 77.25$ & $\$ 20.50$ & $\$ 1,583.72$ \\
\hline (afd) & $\mathrm{P}_{\mathrm{N}} 10$ & $\$ 25.00$ & $\$ 20.50$ & $\$ 512.50$ \\
\hline & & & $V_{N S P}$ & $\$ 13,238.56$ \\
\hline
\end{tabular}

\section{Conclusion}

With the use of the equivalent equations, a fair balance can be facilitated between the parties, debtor (s) and creditor (s). In other words, the debtor party who, due to lack of economic resources, will is unable to settle his previously contracted commitments; will seek to extend the time to pay his debt. 
On the other hand, his creditor, by not recovering his capital plus the originally agreed interest, may receive another additional income. This is derived from the different calculations that show the inclusion of the variables: transaction costs, adjustment to the interest generated in the revaluation of the documents that have expired, and any default interest that is agreed, according to the model of equations to be used for debt restructuring.

These hypothetical scenarios that supported the development of mathematical modeling are consistent with the original proposals that García-Santillán and Vega-Lebrún (2008) raised at the beginning, which were evolving in García-Santillán, Venegas-Martínez and Escalera-Chávez, (2014), García-Santillán, Howe and Venegas-Martínez (2016).

It is evident that mathematical models with equivalent equations seek the balance between the debtor and creditor parties. However, the data with which the models are fed must be previously agreed by the debtor and creditor. Thus, a consensus must exist between the parties in relation to the interest rates used for indexation, for the discount, the percentage of transaction costs, and finally the spot exchange rates according to the currency in which the debt has been agreed and the conversion to another currency is desired.

\section{References}

CFI-Corporate Finance Institute (2019). Debt Restructuring: The process of refinancing existing obligations. Retrieved of: https://rb.gy/yefzrt

García-Santillán A, Vega-Lebrún CA.(2008). Reestructuración de la deuda mediante un factor común y la modelización con ecuaciones equivalentes. Contribuciones a la Economía. 2008.

García-Santillán A, Venegas-Martínez F, Escalera-Chávez M. (2014). Modeling restructuring debt with equivalent equations: Theoretical and practical implications. American Review of Mathematics and Statistics. 2014; 2: 91-106.

García-Santillán A, Howe Andrew J, Venegas-Martínez F. (2016). Short- and Long-term Debt Restructuring through Equivalent Equations: The Case of a Company in the Services Sector. Istanbul University Journal of the School of Business. 2016; 46: 133142.

García-Santillán A. (2019). An algorithm to renegotiate debt through equivalent equations and transaction costs: a proposal for the field of financial education. International Electronic Journal of Mathematics Education IEJME. 2019; 14: 123-136.

García-Santillán, A. (2019b). Present and Future Values Equations, Transaction Costs and Exchange Rate, As Variables Integrated into an Algorithm for Debt Restructuring Model . J Math Stat Res 1(3): 113

Moreno-Garcia E, García-Santillán A, Bermúdez A, Almeida PC. (2015). Restructuring debt proposal in three hypothetical scenarios: Equal payments, different amounts and one unknown payment, different amounts and three unknown payment. Journal of Progressive Research in Mathematics. 4: 233-247. 